Research Article

\title{
Attitude of medical students towards the use of audio visual aids during didactic lectures in pharmacology in a medical college of central India
}

\author{
Mehul Agrawal*, Rajanish Kumar Sankdia
}

\begin{abstract}
Department of Pharmacology, Chirayu Medical College \& Hospital, Bhopal, MP, India

Received: 07 January 2016

Accepted: 03 February 2016

*Correspondence to:

Dr. Mehul Agrawal,

Email: drmehulagrawal@ yahoo.co.in
\end{abstract}

Copyright: (C) the author(s), publisher and licensee Medip Academy. This is an openaccess article distributed under the terms of the Creative Commons Attribution NonCommercial License, which permits unrestricted noncommercial use, distribution, and reproduction in any medium, provided the original work is properly cited.

\begin{abstract}
Background: Students favour teaching methods employing audio visual aids over didactic lectures not using these aids. However, the optimum use of audio visual aids is essential for deriving their benefits. During a lecture, both the visual and auditory senses are used to absorb information. Different methods of lecture are - chalk and board, power point presentations (PPT) and mix of aids. This study was done to know the students' preference regarding the various audio visual aids, with an aim to improve their use in didactic lectures.

Methods: A questionnaire-based observational study (annexure-1) in all the medical students of 3rd, 4th and 5th semester MBBS attending theory classes in the department of Pharmacology in Chirayu Medical College, Bhopal was conducted.

Results: In our study, as a whole, majority (87\%) of students preferred a combination of audio visual aids during a didactic lecture. Ninety seven students participated in the study out of which forty students $(41 \%)$ were male and fifty seven students (59\%) were female. Students told that the lectures using mix of aids were well organized and the lecture contents were well informative. As compared to blackboard the lectures taken on PowerPoint were clearly visible and well audible to all the students of the classroom. Majority $67 \%$ $(n=65)$ of the respondents were interested in taking notes during class and preferred mix of aids, although 33\%, $(n=32)$ students preferred hand outs, if available, over self-written notes.

Conclusions: In our study we found that students preferred mixture of audio visual aids over other teaching methods. Teachers should consider the suggestions given by the students while preparing their lectures.
\end{abstract}

Keywords: Audio visual aids, Power point, Chalk and board, Mix of aids

\section{INTRODUCTION}

Lectures have been the most common form of teaching and learning since ancient times. ${ }^{1}$ During a lecture, both the visual and auditory senses are used to absorb information. ${ }^{2}$

Pharmacology, in medical science, is an ever changing medical subject. It is accepted that reviewing the teaching and evaluation methods by feedback from students and modification of methodologies accordingly is very important for the undergraduate medical teaching. Attempts have been made all over India to make the teaching of pharmacology more interesting and relevant. ${ }^{3}$
In recent years, undergraduate training in pharmacology has been revolutionized with adoption of new methods of teaching including computer assisted learning, use of audio visual aids, role plays and clinical pharmacology studies. The use of electronic media has become common in medical colleges, as in other colleges and universities. ${ }^{4}$

This study was done to know the students' preferences regarding the lectures using PowerPoint (PPT) presentations and the traditional 'chalk and talk' method with an aim to improve their use in didactic lectures in pharmacology. 


\section{METHODS}

A questionnaire-based (Annexure-1) observational study in all the medical students of $3^{\text {rd }}, 4^{\text {th }}$ and $5^{\text {th }}$ semester MBBS attending theory classes in the department of Pharmacology in Chirayu Medical College, Bhopal was conducted after getting permission from research committee of the college.

The students were asked to fill in the questionnaire about their assessment of the impact of the pharmacology lectures delivered by three different methods of lecture delivery, viz. Chalk and board PPT presentation and mix of aids. For each of the lecture given by a different lecture delivery method, the students were asked to grade each of the following parameter out of a maximum mark of 5:

1. Were the lectures well organized?

2. Were the lectures well audible?

3. Were lecture contents clearly visible?

4. Was lecture content well informative?

5. Did lecture stimulated interest in further reading?

6. Did lecture improve your understanding of topic?

7. Were you able to take notes in class?

8. Were Diagrams and Flow charts better perceived in lecture?

Ninety seven students successfully completed the study and their responses were analysed.

Questionnaire collected demographic and other relevant information about the student respondents. The gender and nationality of the respondents were noted. The information as to whether the student had studied in a government/private school and medium of instruction at the school were recorded, questionnaire also consisted of
7 statements regarding audio visual aids. The students were asked to answer legibly and to tick mark the appropriate answers wherever required. No personal identifying information was obtained. The students were informed that their participation in the study was voluntary.

The comparison of the preferences of visual aids with respect to gender, schooling and the medium of instruction in the schools was done by using the Chisquare test and rest of the questions were analysed using one way ANOVA test. $\mathrm{P}$ values $<0.05$ were considered to be statistically significant. The data was analysed by using the Statistical Package for Social Sciences (SPSS), version 11 .

\section{RESULTS}

Ninety seven students participated in the study out of which forty students (41\%) were male and fifty seven students (59\%) were female. All 97 students (100\%) were from India. Out of 97 students maximum students were from Madhya Pradesh (M.P.) i.e. 80 students (82\%) and 6 (6\%) students were from Uttar Pradesh, 3 (3\%) students were from Gujarat, $3(3 \%)$ students were from Chhattisgarh, 2 (2\%) students were from Punjab, 2 (2\%) students were from Delhi and 1 student was from state Bihar.

$87(90 \%)$ students studied in private schools and rest 10 (10\%) students went to the government school. 85 (88\%) students reported medium of instruction at school as English, $11(11 \%)$ reported as Hindi medium and 1 student studied in Gujarati medium school and the visual aid which was predominantly used in the schools, was chalk and board (70.1\%).

Table 1: Students preference of visual aids for various aspects of learning.

\begin{tabular}{|lllll|}
\hline $\begin{array}{l}\text { S. } \\
\text { No }\end{array}$ & Parameters & $\begin{array}{l}\text { Chalk and board } \\
\text { (Total score) }\end{array}$ & $\begin{array}{l}\text { Power point } \\
\text { (Total score) }\end{array}$ & $\begin{array}{l}\text { Mix of AIDS } \\
\text { (Total score) }\end{array}$ \\
\hline 1 & The lectures were well organized & 327 & 374 & 446 \\
\hline 2 & The lectures were well audible & 224 & 377 & 368 \\
\hline 3 & The lecture contents were clearly visible & 271 & 380 & 374 \\
\hline 4 & The lecture contents were well informative & 352 & 377 & 449 \\
\hline 5 & Lecture stimulated my interest in further reading & 333 & 342 & 435 \\
\hline 6 & The lecture improved my understanding of topic & 348 & 345 & 442 \\
\hline 7 & I was able to take my notes in class & 343 & 319 & 442 \\
\hline 8 & Diagrams and Flow charts were better perceived in lecture & 337 & 376 & 445 \\
\hline & Total score & 2535 & 2890 & 3401 \\
\hline
\end{tabular}

In our study, as a whole, the respondents preferred a combination of audio visual aids during a didactic lecture (Table 1, Figure 1).
Students told that the lectures using mix of aids were well organized and the lecture contents were well informative when both chalk and board as well as PowerPoint were used for as teaching methods The perception of diagrams 
and flow charts was better with mix of aids and this method of teaching also stimulated their interest in further reading of topic taught in the lectureAlso there was improved understanding of topic by the students when mix of aids were used as teaching method.

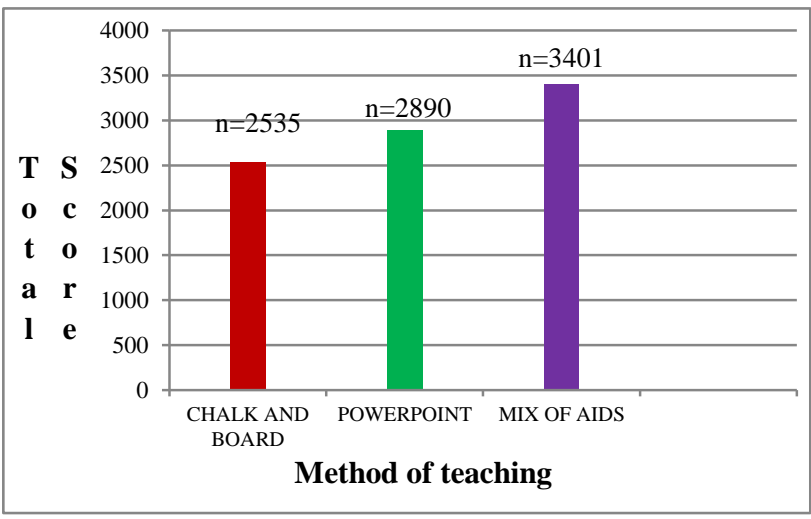

\section{Figure 1: Visual aids preferred during didactic lectures.}

As compared to blackboard the lectures taken on PowerPoint were clearly visible and well audible to all the students of the classroom.

As far as the matter of taking notes in class is concerned students preferred mix of aids over blackboard and PowerPoint, if used as a teaching method alone.

For a full description of the individual statements, kindly refer to the questionnaire in the appendix.

Majority $67 \%(n=65)$ of the respondents were interested in taking notes during class, although 33\%, $\quad(n=32)$ students preferred hand outs, if available, over selfwritten notes. With respect to gender, both male $(65 \%)$ and female $(70 \%)$ students preferred notes over handouts.

Majority (87\%) of students preferred mix of aids as teaching method over blackboard and power point. However, $8 \%$ of students liked PowerPoint and remaining $5 \%$ preferred chalk and board over mix of aids for teaching purpose.

As far as schooling is concerned most of the students $(89 \%)$ studied in private schools and only $(11 \%)$ of students studied in government school. Now, most of the students $(88 \%)$ belonging to the private schools preferred mix of aids while 9\% preferred PowerPoint and 3\% preferred blackboard. While students belonging to government schools mostly preferred mix of aids $(80 \%)$ while $10 \%$ student preferred PowerPoint and remaining $10 \%$ preferred chalk and board as teaching method.

Most of the students $(87 \%)$ studied in the schools where medium of instruction at school was English and remaining $(13 \%)$ belonged to Hindi medium schools. Now, $84 \%$ students belonging to Hindi medium schools preferred mix of aids as teaching method while $8 \%$ of students liked PowerPoint and remaining $8 \%$ preferred chalk and board. Similarly, $88 \%$ students of English medium schools preferred mix of aids while $8 \%$ students wanted PowerPoint as teaching media and $4 \%$ students liked chalk and board method.

As far as matter of suggestions is concerned $82(84.5 \%)$ students gave suggestions to improve teaching methods.

\section{For chalk and board method some of the following useful suggestions were given}

1. Use of coloured chalks

2. Line diagrams and graphs should be included

3. Use of collar microphone for good audibility.

4. Handwriting should be good and clearly visible

5. Proper lighting of the blackboard for clear visibility

6. Spellings should be written correctly

\section{For PowerPoint method some of the following useful suggestions were given}

1. Change of slides should be slow so that sufficient time is available for making notes.

2. Animated videos should be included

3. Written material on slides should be in the form of points rather than paragraph

4. Overcrowding of slides should be avoided

5. Proper font size should be used for good visibility

6. Flow charts should be included

7. Simply reading of slide material should be avoided

8. Background of the slides should be white for good visibility

9. Lighting of the classroom should be dim for increasing the visibility

\section{DISCUSSION}

Pharmacology is a Para-clinical subject, taught to the undergraduate students of MBBS in third, fourth and fifth semester and each semester lasting for six months i.e. total study duration is for 18 months. Along with pharmacology students also study other Para-clinical subjects such as microbiology, pathology and forensic medicine, integrated horizontally. During the study period of pharmacology, students learn from didactic theory lectures and problem based learning methods by using various therapeutic problems and practical experiments. ${ }^{5}$ Didactic lectures in our medical college involve use of various teaching methods such as chalk and board, PowerPoint and mix of aids. Questionnaires are being used commonly as a tool to evaluate the various aspects of teaching and learning among the undergraduate medical students. ${ }^{6}$

In our study, questionnaires were distributed among students to study the students' opinion on the use of audio visual aids during didactic lectures in pharmacology. 
Following eight questions were asked for each of the various teaching methods involving chalk and board, PowerPoint and mix of aids. ${ }^{4}$

Were the lectures well organized?

Were the lectures well audible?

Were lecture contents clearly visible?

Was lecture content well informative?

Did lecture stimulated interest in further reading?

Did lecture improve your understanding of topic?

Were you able to take notes in class?

Were Diagrams and Flow charts better perceived in lecture?

Students were instructed to give marks to each question from 1 to 5 according to their preferences for all the three teaching methods. In our study 97 students participated voluntarily and the feedback revealed that the respondents preferred a combination of audio visual aids during a didactic lecture. The students expressed the view that in such lectures, the elucidation of the concept was absolutely clear and that they were inspired for further indepth reading.

The major drawback of didactic lectures is that the students receive the teaching material passively which makes them feel bored and sleepy. To make the lectures interesting increased use of audio visual aids can be effective.

In our study, students felt that the lectures of the teachers were well organised when they used both power point and blackboard as the teaching method as alone power point teaching method or alone chalk and board method made the lecture very boring and monotonous. The total score in mix of aids was 446 which was found significant $(\mathrm{p}<0.0001)$ as compared to the other two teaching methods.

Participants in our study gave feedback that the lectures were well audible when powe rpoint alone was used as a teaching method because the teacher used the dais fitted with microphone all the time during the lecture. The total score was 377 which was found significant $(p<0.0001)$ as compared to chalk and board method, because the teacher teaching on blackboard was not able to use microphone all the time.

Participants in our study gave feedback that the lectures were well visible when power point alone was used as a teaching method because of the proper lighting and clear fonts. The total score was 380 which was found significant ( $\mathrm{p}<0.0001)$ as compared to chalk and board method, because the content written on blackboard was not clearly visible due to poor lighting and improper cleaning of the blackboard and also sometimes the handwriting of the teacher is not well perceived by the students.

In our study, students felt that the lectures of the teachers were well informative when they used both power point and blackboards i.e. mix of aids because some important diagrams and images could be further explained on blackboard. The total score in mix of aids was 449 which was found significant $(\mathrm{p}<0.0001)$ as compared to the other two teaching methods.

Participants in our study gave feedback that the lectures stimulated their interest in further reading when teacher used both power point and blackboard as the teaching method, The total score in mix of aids was 435 which was found significant $(\mathrm{p}<0.0001)$ as compared to the other two teaching methods.

In our study, students felt that the lectures of the teachers were well understood when they used both power point and blackboard i.e. mix of aids because the animated videos and images shown during the lecture made the topic more interesting and easily understandable. The total score in mix of aids was 442 which was found significant $(\mathrm{p}<0.0001)$ as compared to the other two teaching methods.

Participants in our study gave feedback that they were able to take notes in class more effectively when both power point and blackboard i.e. mix of aids were used as teaching method because students are able to match the pace of teacher when he or she is using the blackboard for writing and power point is used only to display the images and show some animated videos related with the topic. In black board-based teaching, the students are active participants and are better able to cope with the teaching speed of the teacher. It motivates an interest in learning and helps in holding attention in the class ${ }^{7}$. The total score in mix of aids was 442 which was found significant $(\mathrm{p}<0.0001)$ as compared to the other two teaching methods.

In our study, students felt that the diagrams and flow charts were better perceived in lecture when both power point and blackboard i.e. mix of aids were used as teaching method, The total score in mix of aids was 445 which was found significant $(\mathrm{p}<0.0001)$ as compared to the other two teaching methods.

The issue of gender in medical education and practice gains new momentum with the rapid increase in the enrolment of women in medical schools and gender could influence academic performance and research activity. ${ }^{8}$ In this study, forty students $(41 \%)$ were male and fifty seven students $(59 \%)$ were female. 


\section{CONCLUSION}

Attitude of medical students towards the use of audio visual aids during didactic lectures in pharmacology was positive and favourable. Teachers should plan to implement feasible student suggestions for further improving their lectures by using a combination of audio visual aids.

Funding: No funding sources

Conflict of interest: None declared

Ethical approval: The study was approved by the Institutional Ethics Committee

\section{REFERENCES}

1. Brown G, Atkins M. Effective Teaching in Higher Education. London, UK: Routledge; 1988.

2. Sahu DR, Supe AN. The art and science of presentation: 35-mm slides. J Postgrad Med. 2000;46:280-285

3. J. Thirunavukkarasu, K. Latha, C. Sathish Babu, C.B. Tharani. A Study on Effectiveness of Different Teaching Methodology in Pharmacology for Under Graduate Students Asian J Exp Biol Sci. 2011;2(3).
4. Seth V, Upadhyaya P, Ahmad M, Kumar V. Impact of various lecture delivery methods in pharmacology. EXCLI Journal 2010;9:96-101.

5. Sudha J. Graduate training programmes in pharmacology in India. Health administrator. 2006;19(1):88-91.

6. Metcalfe DH, Mathura M. Students perception of good and bad teaching: a report of a critical incident study. Medical Education. 1995;29:193-7.

7. Baxi SN, Shah C J, Parmar RD, Parmar D, Tripathi CB. Student's perception of different teaching aids in a medical college. African Journal of Health Professions Education. 2009;1(1):15-6.

8. Hojat M, Glaser K, Gang Xu, Veloski JJ, Christen BE. Gender comparison of medical students psychosocial profiles. Medical Education. 2002;33(5):342-9.

Cite this article as: Agrawal M, Sankdia RK.

Attitude of medical students towards the use of audio visual aids during didactic lectures in pharmacology in a medical college of central India. Int J Basic Clin Pharmacol 2016;5:416-22. 


\section{ANNEXURE-1}

\section{QUESTIONNAIRE}

This questionnaire is designed to help us understand your preferences regarding the various audiovisuals aids used in lecture classes. Participation depends on your willingness. No personal information should be written on the paper (name, roll number).

Please answer legibly and encircle the appropriate answers wherever required. Wherever answer is mix of aids please specify combination of aids.

\section{QUESTIONS:}

1. Country:

2. State:

3. Gender:

4. Medium of instruction at school:

5. Govt. school/ Private school:

6. Visual aids used in medical college:

A. Black board B. Power point (PPT) C. Black board + Power point (PPT)

7. Which visual aid will you prefer for use during didactic lectures in medical college? Please give marks (1 to 5) according to following parameters for chalk and board method.

\begin{tabular}{|c|c|c|c|c|c|}
\hline \multirow[t]{2}{*}{ Parameters } & \multicolumn{5}{|c|}{ Marks } \\
\hline & 1 & 2 & 3 & 4 & 5 \\
\hline \multicolumn{6}{|l|}{ The lectures were well organized } \\
\hline \multicolumn{6}{|l|}{ The lectures were well audible } \\
\hline \multicolumn{6}{|l|}{ The lecture contents were clearly visible } \\
\hline \multicolumn{6}{|l|}{ The lecture contents were well informative } \\
\hline \multicolumn{6}{|l|}{ Lecture stimulated my interest in further reading } \\
\hline \multicolumn{6}{|l|}{ The lecture improved my understanding of topic } \\
\hline \multicolumn{6}{|l|}{ I was able to take my notes in class } \\
\hline Diagrams and Flow charts were better perceived in lecture & & & & & \\
\hline
\end{tabular}

8. Which visual aid will you prefer for use during didactic lectures in medical college? Please give marks (1 to 5) according to following parameters for Power point (PPT).

\begin{tabular}{|c|c|c|c|c|c|}
\hline \multirow[t]{2}{*}{ Parameters } & \multicolumn{5}{|c|}{ Marks } \\
\hline & 1 & 2 & 3 & 4 & 5 \\
\hline \multicolumn{6}{|l|}{ The lectures were well organized } \\
\hline \multicolumn{6}{|l|}{ The lectures were well audible } \\
\hline \multicolumn{6}{|l|}{ The lecture contents were clearly visible } \\
\hline \multicolumn{6}{|l|}{ The lecture contents were well informative } \\
\hline \multicolumn{6}{|l|}{ Lecture stimulated my interest in further reading } \\
\hline \multicolumn{6}{|l|}{ The lecture improved my understanding of topic } \\
\hline \multicolumn{6}{|l|}{ I was able to take my notes in class } \\
\hline Diagrams and Flow charts were better perceived in lecture & & & & & \\
\hline
\end{tabular}


9. Which visual aid will you prefer for use during didactic lectures in medical college? Please give marks (1 to 5) according to following parameters for mix of aids chalk and board + Power point (PPT).

\begin{tabular}{|c|c|c|c|c|c|}
\hline \multirow[t]{2}{*}{ Parameters } & \multicolumn{5}{|c|}{ Marks } \\
\hline & 1 & 2 & 3 & 4 & 5 \\
\hline The lectures were well organized & & & & & \\
\hline The lectures were well audible & & & & & \\
\hline The lecture contents were clearly visible & & & & & \\
\hline The lecture contents were well informative & & & & & \\
\hline Lecture stimulated my interest in further reading & & & & & \\
\hline The lecture improved my understanding of topic & & & & & \\
\hline I was able to take my notes in class & & & & & \\
\hline Diagrams and Flow charts were better perceived in lecture & & & & & \\
\hline
\end{tabular}

10. Do you prefer? A. Hand outs B. Notes taken by you during the lectures

11. Mention THREE important ways in which you think the use of chalk and blackboard as a visual aid can be improved:

12. Mention THREE important ways in which you think the use of LCD projector as a visual aid can be improved: 